\title{
Stemness and plasticity of lung cancer cells: paving the road for better therapy
}

This article was published in the following Dove Press journal:

OncoTargets and Therapy

23 June 2014

Number of times this article has been viewed

Judong Luo ${ }^{1,2, *}$

Xifa Zhou ${ }^{1, *}$

Juan Sebastian Yakisich ${ }^{3}$

'Changzhou Tumor Hospital, Soochow University, Changzhou, ${ }^{2}$ School of Radiation Medicine and Protection, Jiangsu Province Key Laboratory of Radiation Medicine and Protection, Soochow University, Suzhou, People's Republic of China; ${ }^{3}$ Department of Clinical Neuroscience, Karolinska University Hospital Stockholm, Sweden

*These authors contributed equally to this work.
Correspondence: Juan Sebastian Yakisich Department of Clinical Neuroscience R54, Karolinska Institute, Karolinska University Hospital, Sweden,

S-I4I 86, Stockholm, Sweden

Tel +46858589533

Fax +46858589533

Email yakisich@gmail.com
Abstract: Lung cancer is a devastating disease that is responsible for around 160,000 deaths each year in United States. The discovery that lung cancer, like most other solid tumors, contains a subpopulation of cancer stem cells or cancer stem-like cells (CSCs/CS-LCs) that if eliminated could lead to a cure has brought new hope. However, the exact nature of the putative lung CSCs/ CS-LCs is not known and therefore therapies to eliminate this subpopulation have been elusive. A limited knowledge and understanding of cancer stem cell properties and tumor biology may be responsible for the limited clinical success. In this review we discuss the stemness and plasticity properties of lung cancer cells that are critical aspects in terms of developing effective therapies. We suggest that the available experimental evidence obtained from lung cancer cell lines and patients' derived primary cultures does not support a tumor model consistent with the classical CSC model. Instead, all lung cancer cells may be extremely versatile and new models of cancer stem cells may be better working models.

Keywords: cancer stem cells, chemotherapy, interconversion, plasticity, phenotype

\section{Introduction}

Lung cancer is the most common malignancy in the United States and is responsible for around 160,000 death each year. ${ }^{1}$ Tumor recurrence after resection is very common and accounts for the majority of mortality. ${ }^{2}$ The cell of origin of lung cancer has been the subject of considerable debate since its elucidation and may lead to new and perhaps more effective therapies. Histopathologically, lung cancer is divided into two main subtypes: non-small-cell lung cancer (NSCLC) and small-cell lung cancer (SCLC). Each subtype may arise from distinct cells of origin localized in defined microenvironments. ${ }^{3-5}$ It was found that both subtypes contain a subpopulation of rare undifferentiated cells expressing CD133, a cancer stem cells marker. ${ }^{6}$ Cancer stem cells (CSCs) or cancer stem-like cells (CS-LCs) have been found in the majority of cancers and are usually related to chemoresistance and recurrence. ${ }^{7,8}$ Lung cancer with stem cell signatures have been associated with resistance to several anticancer drugs, such as, cisplatin, ${ }^{9,10}$ Epidermal growth factor receptor (EGFR) inhibitors ${ }^{8}$ such as gefitinib, ${ }^{11}$ docetaxel and gemcitabine. ${ }^{12}$ In a simplistic explanation the classical cancer stem cell theory (CSCT) states that CSCs are: a) rare, b) highly resistant to conventional therapies, c) similar to normal stem cells capable of unrestricted self-renewal and multipotent differentiation ${ }^{13,14}$ and thus responsible for tumor recurrence. ${ }^{14-16}$ From a clinical point of view the idea that the elimination of this subpopulation will lead to a cure or at least to dramatic improvement has become a new dogma in the cancer field. ${ }^{17,18}$ It is then not surprising that considerable efforts and resources are being allocated to identify and 
eliminate this fraction. As our knowledge of CSCs improves, the acceptance of the classical CSC theory as a universal model has been questioned and gave rise to alternative models that have different clinical implications.

In contrast to the CSCT, the stemness phenotype model $(\mathrm{SPM})^{19}$ proposes that all cancer cells may have stem cell properties and that the stemness of cancer cells depend on the microenvironment. According to the SPM all cancer cells are potentially tumorigenic and any cancer cell could be responsible for tumor recurrence. Thus, from the clinical point of view, to cure cancer, all cancer cells should be targeted and eliminated at once. Models closely resembling the SPM with similar clinical implications have also been proposed, amongst them: the "complex system model", ${ }^{20}$ the "reprogramming model", ${ }^{21}$ the "dynamic CSC model", ${ }^{22}$ and the "plasticity model". ${ }^{23}$ The idea that CSCs possess constantly evolving features and are "moving targets" rather than fixed entities is gaining acceptance. ${ }^{24}$

This mini-review will focus on the current knowledge of lung cancer stem cells in order to summarize the findings supporting alternative models of cancer stem cells. Such knowledge is crucial in order to better design new therapies that actually benefit patients.

\section{Search method}

Literature data of relevant studies were conducted using the PubMed (http://www.pubmed.com) and ScienceDirect databases for articles published up to January, 2014 (additional searches were done for a revised version). Relevant terms such as "lung cancer stem cells", "lung cancer stem cells plasticity", "lung cancer stem cells stemness", and many other variants including keywords relevant to the minireview (eg, microenvironment, signaling pathways; see Table 1 and 2) were used. Since this article is a minireview/perspective article, only selected relevant references were included.

\section{Lung cancer stem cells}

Probably the first observation of LCSCs came from the work published by Carney et al in $1982^{25}$ at a time when the CSC hypothesis was not prominent. Later on, putative LCSCs were isolated from a variety of cell lines and tumor specimens. Recent reviews has summarized this findings (see Table 1 and 2 in $^{26}$ and, ${ }^{19}$ respectively). LCSCs have been associated with radioresistance ${ }^{27}$ and chemoresistance..$^{8-11}$ Similar to findings in other tumors LCSCs are able to form spheres $^{28}$ and express stem cell markers such as CD133, CD44, ALDH1, and $\beta$-catenin and were found to be associated with higher recurrence rates. ${ }^{29}$ In summary, there is overwhelming evidence that lung cancers have cells with traits of stem cells. However, there are controversies regarding which model of CSC fits better ${ }^{26}$ in order to be used as a more rational guideline to develop new therapies for this disease.

\section{Modulation of stemness by signaling pathways}

Multiple signaling pathways such as Wnt/beta-catenin, Hedgehog and Notch that appear to be involved in the regulation of stemness in other solid tumors have already been implicated in lung cancer development. ${ }^{4}$ An activated Wnt/ beta-catenin pathway, which in A540 cells up-regulates the stem marker OCT-4, ${ }^{30}$ predicts increased risk of tumor recurrence. ${ }^{31}$ SOX17, which acts as a Wnt signaling inhibitor and

Table I Stemness modulation of LCSCs by signaling pathways

\begin{tabular}{|c|c|c|c|}
\hline Cell type & Signaling pathway & $\begin{array}{l}\text { Effect on } \\
\text { stemness }\end{array}$ & Reference \\
\hline A549 & Wnt/beta-catenin & $\uparrow$ & 30,51 \\
\hline A549, HI299 & Hedgehog & $\uparrow$ & 58,59 \\
\hline HCC, HI339 & Hedgehog & $\uparrow$ & 60 \\
\hline Primary LSCC tumor cells & Hedgehog & $\uparrow$ & 61 \\
\hline A549, $\mathrm{HI} 299$ and $\mathrm{HI} 755$ & Notch-I & $\uparrow$ & 62 \\
\hline $\mathrm{H} 460$ and $\mathrm{H} 66 \mathrm{I}$ & Notch-I & $\uparrow$ & 9 \\
\hline A panel of primary NSCLC & Notch-3 & $\uparrow$ & 63 \\
\hline NSCLC cell lines: $\mathrm{NCl}-\mathrm{HI} 299, \mathrm{NCl}-\mathrm{H} 358$, & Notch & $\uparrow$ & 64 \\
\hline \multicolumn{4}{|l|}{$\mathrm{NCl}-\mathrm{H} 44 \mathrm{I}, \mathrm{NCl}-\mathrm{H} 460$, and $\mathrm{A} 549$} \\
\hline HI650, HI975, A549 & EGFR/Src/Akt & $\uparrow$ & 65 \\
\hline Several lung AD cell lines including HI975 and PC-3 & Akt/Sox2 & $\uparrow$ & 66 \\
\hline A549 & pAkt & $\uparrow$ & 67 \\
\hline A549 & IGFIR/PI3K/AKT/GSK3 $\beta$ & $\uparrow$ & 68 \\
\hline Gefitinib-resistant A549 cells & CXCR4-medated STAT3 pathway & $\uparrow$ & 69 \\
\hline
\end{tabular}

Abbreviations: NSCLC, non-small-cell lung cancer; EGFR, epidermal growth factor receptor; AD, adenocarcinoma; LSCC, laryngeal squamous cell carcinoma; HCC, hepatocellular carcinoma. 
Table 2 Microenvironmental factors implicated in stemness modulation of lung cancer cells

\begin{tabular}{llll}
\hline Cell type & Microenvironmental factor & $\begin{array}{l}\text { Effect on } \\
\text { stemness }\end{array}$ & Reference \\
\hline H-I46 (small-cell lung carcinoma) & & $\uparrow$ & 70 \\
NSCLC cell lines, PC9 and HCC827 & Hypoxia & $\uparrow$ & 7 I \\
A549, NCl-H358 & Hypoxia & $\uparrow$ & 72 \\
A549, PC-I4, and CRL-5807 & CAF likely via (TGF)- $\beta$ I & $\uparrow$ & 73 \\
A549 & VAF & $\uparrow$ & 74 \\
A549 & TGF- $\beta$ I & $\uparrow$ & 75 \\
A549 & IL-8 & $\uparrow$ & 75 \\
A549 and HTBI77 & VEGF & $\uparrow$ & 76 \\
CMTI67 & tMVs & & 77 \\
\hline
\end{tabular}

Abbreviations: CAF, cancer associated fibroblasts; VAF, vascular adventitial fibroblasts; TGF, transforming growth factor; IL-8, interleukin 8; VEGF, vascular endothelial growth factor; NSCLC, non-small-cell lung cancer; CAF, cancer-associated fibroblasts; VAF, vascular adventitial fibroblasts; tMVs, tumor microvesicles.

inhibits proliferating cells, is frequently downregultated in lung cancer cells. ${ }^{32}$ Hedgehog is also linked to lung cancer development ${ }^{33}$ and plays a role in the maintenance of lung cancer cells stemness.

Increased Notch activity enhances epithelial-mesenchymal transition in gefitinib-acquired resistant lung cancer cells ${ }^{11}$ and has been correlated with poor clinical outcome in NSCLCs patients without TP53 mutations. Approximately 30\% of NSCLCs showed increased Notch activity due to loss of the counteracting function of Numb. In approximately $10 \%$ of the cases a gain of function mutation of the NOTCH-1 gene ${ }^{34}$ was obderved. Numb acts as an inhibitor of the Notch receptor signaling pathway but it is also connected to Hedgehog- and TP53-activated pathways, regulating multiple functions such as maintenance of stem cell compartments, regulation of cell polarity and adhesion, and migration. ${ }^{35}$

\section{Stemness modulation of LCSCs by the microenvironment}

The tumor microenvironment contains a variety of malignant and non-malignant cell $\mathrm{s}^{36}$ and plays a key role in the regulation of the epithelial-mesenchymal transition $(\mathrm{EMT})^{37}$ that is associated with the acquisition of stem cell traits. ${ }^{38}$ Specifically, NSCLC induction of EMT by TGF $\beta-1$ has been shown to increase stemness. ${ }^{39}$ Interactions between tumor cells and the stroma cells are therefore considered candidate targets for therapeutical interventions. ${ }^{40}$ In particular, in lung cancer, cancer associated fibroblasts (CAFs) have been found to promote the stemness of cancer cells (Table 2). It seems that fibroblasts in general have a promoting effect as they has been used as feeder cells to establish LCSC cultures. ${ }^{41}$ There is evidence that tumor associated macrophages (TAMs) play an important role in cancer progression and metastasis in NSCLC. ${ }^{42}$ TAMs depending on the influence of various stimuli in the tumor microenvironment can develop into a tumor-inhibitory (M1) or tumor-promoting (M2) phenotype. ${ }^{36,43}$ Hypoxia that is commonly associated with resistance to radiation and chemotherapy in lung cancer ${ }^{44}$ is also a known promoter of stemness in LCSCs most likely via activation of the Notch pathway. ${ }^{37,38}$

\section{Plasticity of cancer cells: interconversion between CSCs and non-CSCs in lung tumors}

Cellular plasticity can be defined as the property or ability of cells to reversible change their phenotype. ${ }^{45}$ There is an increasing acceptance that cancer cells display variable degrees of plasticity. ${ }^{46-48}$ The classical cancer stem cell theory proposed a hierarchical and unidirectional organization where CSCs can give origin to more differentiated cells. Due to the unidirectional organization, differentiated cells have limited plasticity and are unable to originate new CSCs. ${ }^{20,22}$ In contrast, the stemness phenotype model initially suggested that cancer cells are not hyerachically organized and can interconvert into each other. ${ }^{19}$ This property expands the plasticity of cancer cells (that can undergo both differentiation and dedifferentiation) since in theory a single non-CSC can originate a new tumor and re-establish a new pool of CSCs. Perhaps the more convincing argument for a lack of hierarchical organization in lung cancer cells would be a direct observation of the conversion from a non-CSCs phenotype to a CSCs phenotype and vice versa as has been recently observed in other systems. ${ }^{49}$ In fact recently Akunuru et al, ${ }^{50}$ provided direct experimental evidence of interconversion between different phenotypic subpopulations of non-small cell lung adenocarcinoma (NSCLA). In that study, interconversion was observed not only between CSCs that were phenotypically different but also between CSCs and non-CSCs. This is consistent with the prediction of the SPM. Evidence that the culture conditions alters the phenotype of lung cancer cells was reported in $1984,{ }^{51}$ long before the isolation of putative LCSCs. 
More surprising, the plasticity of lung cancer stem cells seems to be not limited only to specific tissues. Zhang et al, found that the SCLC cell line NCI-H446 can also differentiate to neurons, adipocytes, and osteocytes. ${ }^{52}$ In the cell line LC-42 expression of the stem cell marker CD133 does not correlate with tumorigenic potential. ${ }^{53}$ The recent observation that committed epithelial cells can differentiate in vivo into stem cells ${ }^{54}$ provides supporting evidence that stemness may be a general porperties of all cells. ${ }^{55}$

\section{Implication for cancer therapy}

Both extreme models of LCSC have also extreme clinical implications. In the classical CSC model, the hierarchical organization gives CSCs a predominant role in cancer resistance and tumor recurrence. Therefore, eliminating this fraction is considered a crucial target and considerable resources are being used in identifying this rare subpopulation and developing strategies to eliminate them. ${ }^{56}$ On the other hand, the SPM and similar alternative models propose that virtually all cancer cells are potentially tumorigenic. Thus, to have a significant impact on cancer treatment all cancer cells should be eliminated at once to prevent tumor progression and relapse. One aspect of tumor biology that is poorly investigated is the potential dynamic of the microenvironment due to external influences. In the classical CSC model, due to its hierarchical nature, CSCs can produce non-CSCs but not in the other way. It is then expected that microenvironmental changes in tumor regions with non-CSCs will have little therapeutic impact but similar changes in tumor regions with CSCs are potential promising avenues to explore for therapies targeting the CSC-microenvironment.

\section{Conclusion}

A better understanding of cancer stem cell biology in lung cancer is essential to develop effective therapies. At present there is increasing evidence suggesting that LCSCs are a dynamic subpopulation harboring a high degree of plasticity and not fixed entities. The complex interaction between a) a dynamic cancer cell phenotype that can interconvert from a pure non-CSC phenotype to a pure CSC phenotype in combination with $b$ ) a dynamic microenvironment that can either promote or suppress cancer stemness adds a significant challenge to the development of novel treatment for lung cancer. A similar scenario has been recently recognized in ovarian cancer. ${ }^{57}$ This complex interaction should be taken into consideration at the early stages of preclinical research to increase the chances of a successful translation into clinical practice.

\section{Acknowledgement}

This study was supported by grants from the Swedish Research Council and the Karolinska Institute.

\section{Disclosure}

The authors report no conflicts of interest.

\section{References}

1. Fedor D, Johnson WR, Singhal S. Local recurrence following lung cancer surgery: Incidence, risk factors, and outcomes. Surg Oncol. 2013;22(3):156-161.

2. Taylor MD, Nagji AS, Bhamidipati CM, et al. Tumor recurrence after complete resection for non-small cell lung cancer. Ann Thorac Surg. 2012;93(6):1813-1820.

3. Hanna JM, Onaitis MW. Cell of origin of lung cancer. $J$ Carcinog. 2013;12:6.

4. García Campelo MR, Alonso Curbera G, Aparicio Gallego G, Grande Pulido E, Antón Aparicio LM. Stem cell and lung cancer development: blaming the Wnt, Hh and Notch signalling pathway. Clin Transl Oncol. 2011;13(2):77-83.

5. Galluzzo P, Bocchetta M. Notch signaling in lung cancer. Expert Rev Anticancer Ther. 2011;11(4):533-540.

6. Eramo A, Lotti F, Sette G, et al. Identification and expansion of the tumorigenic lung cancer stem cell population. Cell Death Differ. 2008;15(3):504-514.

7. Zhao J, Ma MZ, Ren H, et al. Anti-HDGF Targets Cancer and Cancer Stromal Stem Cells Resistant to Chemotherapy. Clin Cancer Res. 2013;19(13):3567-3576.

8. Shien K, Toyooka S, Yamamoto H, et al. Acquired resistance to EGFR inhibitors is associated with a manifestation of stem cell-like properties in cancer cells. Cancer Res. 2013;73(10):3051-3061.

9. Liu YP, Yang CJ, Huang MS, et al. Cisplatin selects for multidrugresistant CD133+ cells in lung adenocarcinoma by activating Notch signaling. Cancer Res. 2013;73(1):406-416.

10. Barr MP, Gray SG, Hoffmann AC, et al. Generation and characterisation of cisplatin-resistant non-small cell lung cancer cell lines displaying a stem-like signature. PLoS One. 2013;8(1):e54193.

11. Xie M, Zhang L, He CS, et al. Activation of Notch-1 enhances epithelialmesenchymal transition in gefitinib-acquired resistant lung cancer cells. J Cell Biochem. 2012;113(5):1501-1513.

12. Pasini A, Paganelli G, Tesei A, Zoli W, Giordano E, Calistri D. Specific Biomarkers Are Associated with Docetaxel and Gemcitabine-Resistant NSCLC Cell Lines. Transl Oncol. 2012;5(6):461-468.

13. Lundin A, Driscoll B. Lung cancer stem cells: Progress and prospects. Cancer Lett. 2013;338(1):89-93.

14. O'Flaherty JD, Barr M, Fennell D, et al. The cancer stem-cell hypothesis: its emerging role in lung cancer biology and its relevance for future therapy. J Thorac Oncol. 2012;7(12):1880-1890.

15. Alison MR, Lin WR, Lim SM, Nicholson LJ. Cancer stem cells: in the line of fire. Cancer Treat. Rev. 2012;38(6):589-598.

16. Levina V, Marrangoni A, Wang T, et al. Elimination of human lung cancer stem cells through targeting of the stem cell factor-c-kit autocrine signaling loop. Cancer Res. 2010;70(1):338-346.

17. Wu X, Chen H, Wang X. Can lung cancer stem cells be targeted for therapies? Cancer Treat Rev. 2012;38(6):580-588.

18. Gorelik E, Lokshin A, Levina V. Lung cancer stem cells as a target for therapy. Anticancer Agents Med Chem. 2010;10(2):164-171.

19. Cruz MH, Siden A, Calaf GM, Delwar ZM, Yakisich JS. The stemness phenotype model. ISRN Oncology. 2012;2012:392647.

20. Laks DR, Visnyei K, Kornblum HI. Brain tumor stem cells as therapeutic targets in models of glioma. Yonsei Med J. 2010;51(5): 633-640

21. Li Y, Laterra J. Cancer stem cells: distinct entities or dynamically regulated phenotypes? Cancer Res. 2012;72(3):576-580. 
22. Vermeulen L, de Sousa E Melo F, Richel DJ, Medema JP. The developing cancer stem-cell model: clinical challenges and opportunities. Lancet Oncol. 2012;13(2):e83-e89.

23. Marjanovic ND, Weinberg RA, Chaffer CL. Cell Plasticity and Heterogeneity in Cancer. Clin Chem. 2013;59(1):168-179.

24. Hu Y, Yu X, Liu S, Liu S. Cancer stem cells: a shifting subpopulation of cells with stemness? Med Hypotheses. 2013;80(5):649-655.

25. Carney DN, Gazdar AF, Bunn PAJ, Guccion JG. Demonstration of the stem cell nature of clonogenic tumor cells from lung cancer patients Stem Cells. 1982;1(3):149-164.

26. Alamgeer M, Peacock CD, Matsui W, Ganju V, Watkins DN. Cancer Stem Cells in Lung Cancer: Evidence and Controversies. Respirology. 2013;18(5):757-764.

27. Xia P, Gou WF, Wang JJ, et al. Distinct Radiosensitivity of Lung Carcinoma Stem-Like Side Population and Main Population Cells. Cancer Biother Radiopharm. 2013;28(6):471-478.

28. Morrison BJ, Steel JC, Morris JC. Sphere culture of murine lung cancer cell lines are enriched with cancer initiating cells. PLoS One. 2012;7(11):e49752.

29. Okudela K, Woo T, Mitsui H, Tajiri M, Masuda M, Ohashi K. Expression of the potential cancer stem cell markers, CD133, CD44, ALDH1, and $\beta$-catenin, in primary lung adenocarcinoma - their prognostic significance. Pathol Int. 2012;62(12):792-801.

30. Teng Y, Wang X, Wang Y, Ma D. Wnt/beta-catenin signaling regulates cancer stem cells in lung cancer A549 cells. Biochem Biophys Res Commun. 2010;392(3):373-379.

31. Shapiro M, Akiri G, Chin C, et al. Wnt pathway activation predicts increased risk of tumor recurrence in patients with stage I nonsmall cell lung cancer. Ann Surg. 2013;257(3):548-554.

32. Yin D, Jia Y, Yu Y, et al. SOX17 methylation inhibits its antagonism of Wnt signaling pathway in lung cancer. Discov Med. 2012;14(74): $33-40$.

33. Velcheti V, Govindan R. Hedgehog signaling pathway and lung cancer. J Thorac Oncol. 2007;2(1):7-10.

34. Westhoff B, Colaluca IN, D'Ario G, et al. Alterations of the Notch pathway in lung cancer. Proc Natl Acad Sci U S A. 2009;106(52): 22293-22298.

35. Pece S, Confalonieri S, Romano PR, Di Fiore PP. NUMB-ing down cancer by more than just a NOTCH. Biochim Biophys Acta. 2011;1815(1):26-43.

36. Quatromoni JG, Eruslanov E. Tumor-associated macrophages: function, phenotype, and link to prognosis in human lung cancer. Am J Transl Res. 2012;4(4):376-389.

37. Gao D, Vahdat LT, Wong S, Chang JC, Mittal V. Microenvironmental regulation of epithelial-mesenchymal transitions in cancer. Cancer Res. 2012;72(19):4883-4889.

38. Mani SA, Guo W, Liao M-J, et al. The epithelial-mesenchymal transition generates cells with properties of stem cells. Cell. 2008;133(4): 704-715

39. Pirozzi G, Tirino V, Camerlingo R, et al. Epithelial to mesenchymal transition by TGF $\beta-1$ induction increases stemness characteristics in primary non small cell lung cancer cell line. PLoS One. 2011;6(6):e21548.

40. El-Nikhely N, Larzabal L, Seeger W, Calvo A, Savai R. Tumor-stromal interactions in lung cancer: novel candidate targets for therapeutic intervention. Expert Opin Investig Drugs. 2012;21(8):1107-1122.

41. Xu Y, Hu YD, Zhou J, Zhang MH. Establishing a lung cancer stem cell culture using autologous intratumoral fibroblasts as feeder cells. Cell Biol Int. 2011;35(5):509-517.

42. Wang R, Zhang J, Chen S, et al. Tumor-associated macrophages provide a suitable microenvironment for non-small lung cancer invasion and progression. Lung Cancer. 2011;74(2):188-196.

43. Lievense LA, Bezemer K, Aerts JG, Hegmans JP. Tumor-associated macrophages in thoracic malignancies. Lung Cancer. 2013;80(3): 256-262.

44. Willers H, Azzoli CG, Santivasi WL, Xia F. Basic mechanisms of therapeutic resistance to radiation and chemotherapy in lung cancer. Cancer J. 2013;19(3):200-207.
45. Nieto MA. Epithelial plasticity: a common theme in embryonic and cancer cells. Science. 2013;342(6159):1234850.

46. Antoniou A, Hébrant A, Dom G, Dumont JE, Maenhaut C. Cancer stem cells, a fuzzy evolving concept: a cell population or a cell property? Cell Cycle. 2013;12(24):3743-3748.

47. Csermely P, Hódsági J, Korcsmáros T, et al. Cancer stem cells display extremely large evolvability: alternating plastic and rigid networks as a potential Mechanism: Network models, novel therapeutic target strategies, and the contributions of hypoxia, inflammation and cellular senescence. Semin Cancer Biol. In press 2014.

48. Scheel C, Weinberg RA. Phenotypic plasticity and epithelialmesenchymal transitions in cancer and normal stem cells? Int J Cancer. 2011;129(10):2310-2314.

49. Chaffer CL, Brueckmann I, Scheel C, et al. Normal and neoplastic nonstem cells can spontaneously convert to a stem-like state. Proc Natl Acad Sci US A. 2011;108(19):7950-7955.

50. Akunuru S, James Zhai Q, Zheng Y. Non-small cell lung cancer stem/progenitor cells are enriched in multiple distinct phenotypic subpopulations and exhibit plasticity. Cell Death Dis. 2012;3:e352.

51. Terasaki T, Kameya T, Nakajima T, et al. Interconversion of biological characteristics of small cell lung cancer depending on culture conditions. Gann. 1984;75(12):1089-1099.

52. Zhang Z, Zhou Y, Qian H, et al. Stemness and inducing differentiation of small cell lung cancer NCI-H446 cells. Cell Death Dis. 2013;4:e633.

53. Wang P, Suo Z, Wang M, et al. In vitro and in vivo properties of CD133 expressing cells from human lung cancer cell lines. Exp Hematol Oncol. 2013;2(1):16.

54. Tata PR, Mou H, Pardo-Saganta A, et al. Dedifferentiation of committed epithelial cells into stem cells in vivo. Nature. 2013;503(7475): 218-223.

55. Casanova J. Stemness as a cell default state. EMBO Rep. 2012;13(5): 396-397.

56. Peacock CD, Watkins DN. Cancer stem cells and the ontogeny of lung cancer. J Clin Oncol. 2008;26(17):2883-2889.

57. Pasquier J, Rafii A. Role of the microenvironment in ovarian cancer stem cell maintenance. Biomed Res Int. 2013;2013:630782.

58. Zhang S, Wang Y, Mao JH, et al. Inhibition of $\mathrm{CK} 2 \alpha$ downregulates Hedgehog/Gli signaling leading to a reduction of a stemlike side population in human lung cancer cells. PLoS One. 2012; 7(6):e38996.

59. Ahmad A, Maitah MY, Ginnebaugh KR, et al. Inhibition of Hedgehog signaling sensitizes NSCLC cells to standard therapies through modulation of EMT-regulating miRNAs. J Hematol Oncol. 2013;6(1):77.

60. Tian F, Mysliwietz J, Ellwart J, Gamarra F, Huber RM, Bergner A. Effects of the Hedgehog pathway inhibitor GDC-0449 on lung cancer cell lines are mediated by side populations. Clin Exp Med. 2012;12(1): 25-30.

61. Justilien V, Walsh MP, Ali SA, Thompson EA, Murray NR, Fields AP. The PRKCI and SOX2 Oncogenes Are Coamplified and Cooperate to Activate Hedgehog Signaling in Lung Squamous Cell Carcinoma. Cancer Cell. 2014;25(2):139-151.

62. Eliasz S, Liang S, Chen Y, et al. Notch-1 stimulates survival of lung adenocarcinoma cells during hypoxia by activating the IGF-1R pathway. Oncogene. 2010;29(17):2488-2498.

63. Sullivan JP, Spinola M, Dodge M, et al. Aldehyde dehydrogenase activity selects for lung adenocarcinoma stem cells dependent on notch signaling. Cancer Res. 2010;70(23):9937-9948.

64. Hassan KA, Wang L, Korkaya H, et al. Notch pathway activity identifies cells with cancer stem cell-like properties and correlates with worse survival in lung adenocarcinoma. Clin Cancer Res. 2013;19(8): 1972-1980.

65. Singh S, Trevino J, Bora-Singhal N, et al. EGFR/Src/Akt signaling modulates Sox 2 expression and self-renewal of stem-like side-population cells in non-small cell lung cancer. Mol Cancer. 2012;11:73.

66. Narita K, Matsuda Y, Seike M, Naito Z, Gemma A, Ishiwata T. Nestin regulates proliferation, migration, invasion and stemness of lung adenocarcinoma. Int J Oncol. 2014;44(4):1118-1130. 
67. Liu F, Cao X, Liu Z, et al. Casticin suppresses self-renewal and invasion of lung cancer stem-like cells from A549 cells through downregulation of pAkt. Acta Biochim Biophys Sin (Shanghai). 2014;46(1): 15-21.

68. Kim IG, Kim SY, Choi SI, Lee JH, Kim KC, Cho EW. Fibulin-3mediated inhibition of epithelial-to-mesenchymal transition and selfrenewal of ALDH+ lung cancer stem cells through IGF1R signaling. Oncogene. In press 2013.

69. Jung MJ, Rho JK, Kim YM, et al. Upregulation of CXCR4 is functionally crucial for maintenance of stemness in drug-resistant non-small cell lung cancer cells. Oncogene. 2013;32(2):209-221.

70. Das B, Tsuchida R, Malkin D, Koren G, Baruchel S, Yeger H. Hypoxia enhances tumor stemness by increasing the invasive and tumorigenic side population fraction. Stem Cells. 2008;26(7):1818-1830.

71. Murakami A, Takahashi F, Nurwidya F, et al. Hypoxia Increases Gefitinib-Resistant Lung Cancer Stem Cells through the Activation of Insulin-Like Growth Factor 1 Receptor. PLoS One. 2014; 9(1):e86459.

72. Shintani Y, Abulaiti A, Kimura T, et al. Pulmonary Fibroblasts Induce Epithelial Mesenchymal Transition and Some Characteristics of Stem Cells in Non-Small Cell Lung Cancer. Ann Thorac Surg. 2013;96(2):425-433.
73. Hoshino A, Ishii G, Ito T, et al. Podoplanin-positive fibroblasts enhance lung adenocarcinoma tumor formation: podoplanin in fibroblast functions for tumor progression. Cancer Res. 2011;71(14):4769-4679.

74. Tirino V, Camerlingo R, Bifulco K, et al. TGF- $\beta 1$ exposure induces epithelial to mesenchymal transition both in CSCs and non-CSCs of the A549 cell line, leading to an increase of migration ability in the CD133+ A549 cell fraction. Cell Death Dis. 2013;4:e620.

75. Desai S, Laskar S, Pandey BN. Autocrine IL-8 and VEGF mediate epithelial-mesenchymal transition and invasiveness via p38/JNKATF-2 signalling in A549 lung cancer cells. Cell Signal. 2013;25(9): $1780-1791$.

76. Wysoczynski M, Ratajczak MZ. Lung cancer secreted microvesicles: underappreciated modulators of microenvironment in expanding tumors. Int J Cancer. 2009;125(7):1595-1603.

77. Justilien V, Regala RP, Tseng IC, et al. Matrix metalloproteinase-10 is required for lung cancer stem cell maintenance, tumor initiation and metastatic potential. PLoS One. 2012;7(4):e35040.
OncoTargets and Therapy

\section{Publish your work in this journal}

OncoTargets and Therapy is an international, peer-reviewed, open access journal focusing on the pathological basis of all cancers, potential targets for therapy and treatment protocols employed to improve the management of cancer patients. The journal also focuses on the impact of management programs and new therapeutic agents and protocols on

\section{Dovepress}

patient perspectives such as quality of life, adherence and satisfaction The manuscript management system is completely online and includes a very quick and fair peer-review system, which is all easy to use. Visit http://www.dovepress.com/testimonials.php to read real quotes from published authors. 